\title{
CAROTINAEMIA IN A SUCKLING
}

\author{
BY \\ M. L. THOMSON, M.D., M.R.C.P. \\ Assistant Physician, Royal Manchester Children's Hospital
}

The following instance of carotinaemia in a suckling seems of sufficient interest to merit a brief clinical memorandum.

The mother, aged twenty-five, was referred on account of 'jaundice' unaccompanied by any symptoms of ill health. Her last child was born six months previously and weighed $8 \mathrm{lb}$. at birth. The baby was breast fed until two months old, when the mother consulted her practitioner because of the onset of ' jaundice' both in herself and her child. She was advised to stop breast feeding and the baby's ' jaundice' gradually disappeared. The mother's ' jaundice,' however, persisted. On examination of the mother there was sallow yellow pigmentation of the whole body with the exception of the sclera which were clear. Clinical examination was otherwise negative. Investigation showed that the icteric index was 8 , though the serum bilirubin was only $0.1 \mathrm{mgm}$. per cent. By the three-layer test, in which equal parts of serum, alcohol and petroleum ether are shaken and allowed to separate, it was shown that the pigment was extracted by the upper layer of petroleum ether. It was evident, therefore, that the pigmentation was due to carotinaemia. Enquiry into her diet elicited that for the past eleven months she had been eating two to three carrots of some $4 \mathrm{in}$. in length daily in addition to a normal consumption of cabbage and cooked carrots. Her weekly consumption of raw carrots averaged two to three pounds. At the time of the examination she was still eating these quantities.

Examination of the baby showed a plump, wellnourished healthy infant with a slight sallow tint overlying the normal pinkness of the skin. The three-layer test on the baby's serum was negative, the serum bilirubin being $0.2 \mathrm{mgm}$. per cent. and the icteric index 2. The mother said that prior to stopping breast feeding the baby's skin had become quite yellow.

The transmission to a suckling of excess of carotene by the mother's milk is an odd outcome of maternal dietetic excess. 